\title{
Identification of human monoclonal antibodies specific for CCR5 from an antibody library derived from HIV-infected long-term
} non-progressors

\author{
Mei-Yun Zhang*1,2, Bang Vu' ${ }^{1}$, Chih-chin Huang3, Igor Sidirov ${ }^{1}$, \\ Vidita Choudhly ${ }^{1}$, Peter D Kwong ${ }^{3}$ and Dimiter S Dimitrov ${ }^{1}$
}

Address: ${ }^{1}$ Center for Cancer Research Nanobiology Program, National Cancer Institute-Frederick, National Institutes of Health, Frederick, Maryland, 21702, USA, 2SAIC-Frederick, Inc., National Cancer Institute-Frederick, National Institutes of Health, Frederick, Maryland, 21702, USA and ${ }^{3}$ Vaccine Research Center, National Institute of Allergy and Infectious Diseases, National Institutes of Health, Bethesda, Maryland, 20892, USA

* Corresponding author

from 2006 International Meeting of The Institute of Human Virology

Baltimore, USA. 17-2I November, 2006

Published: 21 December 2006

Retrovirology 2006, 3(Suppl I):S6I doi:I0.II86/1742-4690-3-SI-S6I

(c) 2006 Zhang et al; licensee BioMed Central Ltd.

It has been reported that about one quarter of long-term nonprogressors had anti-CCR5 antibodies and such antibodies were not found in disease progressing HIV-1 positive individuals [1]. To identify such antibodies we panned an HIV immune library constructed from bone marrow of three long-term nonprogressors against a synthetic sulfated N-terminal CCR5 peptide (2-15) (R5Nt). Twenty anti-CCR5 monoclonal antibodies were selected that bind to the R5Nt and cell-associated CCR5. Sequence analysis revealed that eighteen clones have $\mathrm{VHs}$ that were derived from the same germline sequence. Preliminary data showed that these antibodies inhibited primary HIV1 isolates from clade $\mathrm{B}$ and $\mathrm{E}$ as tested in a pseudovirus assay. Identification of these anti-CCR5 human monoclonal antibodies indicates possible contribution to mechanisms determining the slow progression or lack of disease in long-term nonprogresssors. The selected antiCCR5 antibodies may have potentials as therapeutics and/ or prophylactics in combination with other HIV-1 neutralizing antibodies and antiretroviral drugs.

\section{References}

I. Pastori C, Weiser B, Barassi C, et al.: Long-lasting CCR5 internalization by antibodies in a subset of long-term nonprogressors: a possible protective effect against disease progression. Blood 107:4825-4833. 